\title{
Technology of demineralized water conditioning
}

\author{
Elena Soloveva ${ }^{1}$, Dmitry Syanov ${ }^{1}$, Alfia Larkina ${ }^{1}$, Tatiana Grishina ${ }^{1}$, Denis Davydov ${ }^{2}$, \\ Artem Davydov ${ }^{2}$ and Ivan Doroshin ${ }^{3, *}$ \\ ${ }^{1}$ State University of Technologies and Management named after K.G.Razumovsky (Bashkir branch), \\ Smolenskaya Street, 34, Meleuz, 453850, Russia \\ ${ }^{2}$ Plekhanov Russian University of Economics, Stremyanny lane 36, Moscow, 117997, Russia \\ ${ }^{3}$ Moscow State University of Civil Engineering, Yaroslavskoeshosse, 26, Moscow, 129337, Russia
}

\begin{abstract}
The aim of this study is to improve the technological schemes of demineralized water conditioning of autonomous objects, which provide automation of processes for obtaining drinking water from distillate at the autonomous objects and meet the requirements of compactness, reliability, energy intensity, environmental friendliness, and safety of service. As a result of the study, methods and materials for the mineralization, deodorization and disinfection of demineralized water were selected, the factors influencing the efficiency of the demineralized water conditioning processes were determined, and the optimal conditions for these processes were determined.
\end{abstract}

\section{Introduction}

The development of autonomous objects is constantly characterized by an increase in the duration of navigation of ships of almost all classes and assignments. This circumstance dictates the need to improve the living conditions on ships. Providing personnel with fresh water is one of the defining indicators of habitability.

Replenishment of fresh water is carried out from demineralization plants installed at autonomous objects to ensure the operation of power plants. Demineralized water obtained from demineralization plants, due to the low content of ions of calcium, magnesium, sodium and other elements is unsuitable for drinking purposes [1].

Currently used equipment and methods for the preparation of drinking water from distillate at autonomous objects have a number of significant disadvantages. These disadvantages are associated with the use of outdated equipment and technological scheme, the extensive use of manual labor, the complexity of the design, and significant operating costs.

Therefore, the development of an optimal technological scheme for water conditioning (at autonomous objects) that eliminates the noted disadvantages and effective small-sized automated monoblock is an important scientific task.

\footnotetext{
* Corresponding author: livandoroshin@rambler.ru
} 


\section{Materials and methods}

Let us consider the structural features of mineralizers used in autonomous objects. For example, mineralization of demineralized water by the reagent method requires a set of salts containing many components. The components are introduced in a certain order, at intervals until the previous component is completely dissolved. Loading of salt in mineralization tanks is done manually. This process takes a long time and requires constant monitoring. Similar difficulties arise during the disinfection process [2].

The analysis of water conditioning methods has shown that the most promising method of mineralization at autonomous objects is the method of enriching the distillate with hardness salts, which passes through a layer of granular filler material. The most promising methods of disinfection are physical (non-reagent) methods.

It is necessary to improve the technological schemes of conditioning demineralized water at autonomous objects and to develop a compact unit (monoblock) providing automation of the processes of obtaining drinking water from demineralized water at autonomous objects. Currently, such technical means are not available [3].

At the same time, a related problem emerged - the need to create possible options for a control and monitoring system on the basis of common circuit elements with their minimum variety (maximum uniformity).

\section{Results}

In connection with the above, the optimal for monoblock structure of the technological scheme of demineralized water conditioning was substantiated and selected (Fig. 1).

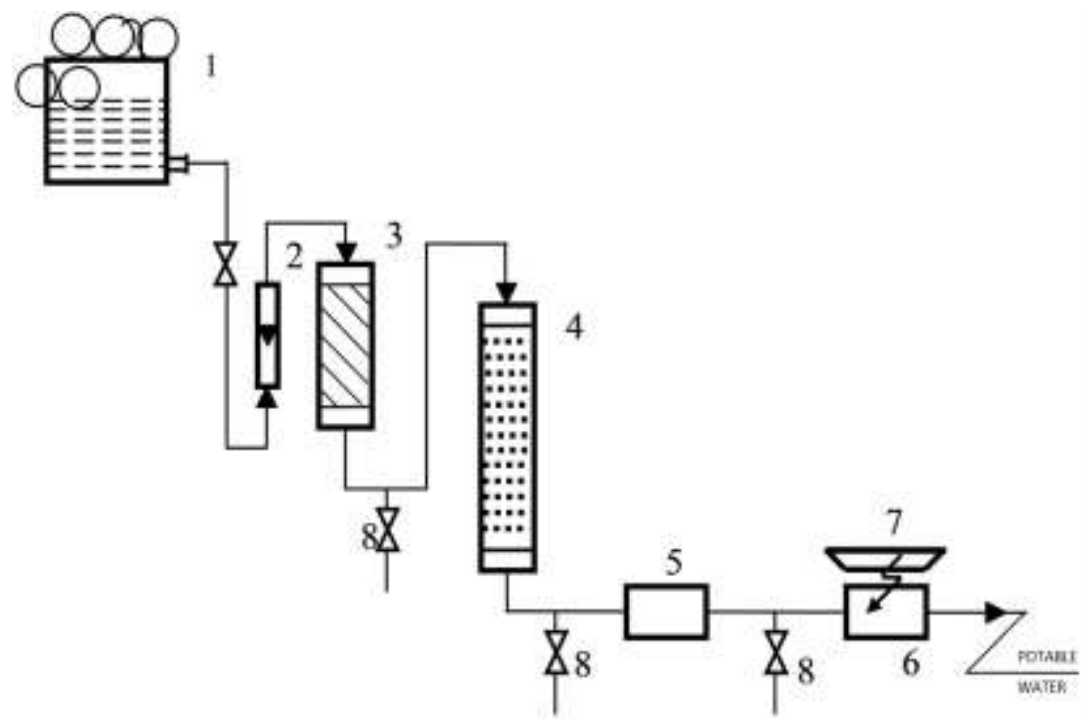

Fig. 1. Technological scheme of conditioning demineralized water, where: 1 - tank with distillate; 2 rotameter; 3 - filter-mineralizer; 4 - filter with activated carbon; 5 - filter cartridge; 6 - cell for water treatment with UV rays; 7 - UV apparatus "Photon"; 8 - samplers.

According to the developed scheme, the distillate obtained in a laboratory water distiller and collected in a container was sent to the filter with a load of poorly soluble calcium and magnesium compounds. Then the treated water entered the filter with activated carbon. Further, filter cartridge made of polypropylene fiber is installed for fine cleaning of 
mechanical particles. For the final treatment of water - disinfection - water entered the specially designed cell 6, in which it was subjected to UV irradiation [4].

Samples for physico-chemical analyzes were taken after each element of water treatment. The content of ions of $\mathrm{Ca} 2+, \mathrm{Mg} 2+, \mathrm{HCO} 3, \mathrm{SO} 4, \mathrm{pH}$, organoleptic, bactericidal effect were controlled.

The most accessible natural minerals were studied: marble, dolomite, magnesite, gypsum, a mixture of dolomite with gypsum.

For a more effective dissolution of minerals and saturation of the distillate with hardness salts, comparative tests were carried out on a distillate with different temperatures and carbon dioxide content $\left(\mathrm{CO}_{2}\right)$ according to the reactions:

$\mathrm{CaCO}_{3}$ (hard) $\leftrightarrow \mathrm{CaCO}_{3}$ (sol.)

$\mathrm{CaCO}_{3}$ (sol.) $+\mathrm{CO}_{2} \rightarrow \mathrm{Ca}\left(\mathrm{HCO}_{3}\right)_{2} \rightarrow \mathrm{Ca}^{2+}+2 \mathrm{HCO}_{3}$

$\mathrm{MgCO}_{3}$ (sol.) $+\mathrm{CO}_{2} \rightarrow \mathrm{Mg}\left(\mathrm{HCO}_{3}\right)_{2} \rightarrow \mathrm{Mg}^{2+}+2 \mathrm{HCO}_{3}$

It should be noted that the distillate usually contains dissolved $\mathrm{CO} 2$ and has a weakly acidic reaction $(\mathrm{pH}=5.0)$.

On the basis of experimental data on the study of the dissolution dynamics of gypsum, it can be recommended for mineralization of distillate, mixed with other minerals, for example, dolomite. The advantage of this mixture is that dolomite perfectly adjusts the $\mathrm{pH}$ of the distillate, the value of which is often $5.0 \ldots 5.5$. The missing amount of hardness salts as well as SO4 ion can be added by dissolving the gypsum.

Since gypsum has a relatively higher solubility compared to other minerals, it is loaded into the filter not in the form of small grains, like marble or dolomite, but in large pieces.

When studying the solubility of a mixed load (dolomite and gypsum), the water treated in a filter-mineralizer acquires the necessary hardness. Treating the distillate in such a filter also contributes to an increase in the $\mathrm{pH}$ of the filter to $\mathrm{pH}=7.1 \ldots 7.6$.

It was established that the mineralization (enrichment) of the distillate with ions of calcium, magnesium and sulphate is provided by $90 \%$ due to the dissolution of gypsum and by $10 \%$ due to the dissolution of dolomite. Consequently, the loading and reloading of filter materials during operation must be carried out in the same ratio, namely, for nine parts of gypsum - one part of dolomite.

To optimize the processes of dissolution of minerals, studies were carried out using the methods of multifactor planning of the experiment. The following factors were taken as factors significantly influencing the process:

1. V - filtration rate, $\mathrm{m} / \mathrm{s}\left(\mathrm{x}_{1}\right)$;

2. $\mathrm{T}$ - water temperature, ${ }^{\circ} \mathrm{C}\left(\mathrm{x}_{2}\right)$;

3. $\mathrm{C}$ - content of $\mathrm{CO}_{2}$ in water, $\mathrm{mg} / \mathrm{l}\left(\mathrm{x}_{3}\right)$.

The optimal content of $\mathrm{Ca}^{2+}$ and $\mathrm{Mg}^{2+}$ ions in water was taken as the main parameter for optimizing Y.

$$
\mathrm{Y}=\sum(\mathrm{Ca}+\mathrm{Mg})
$$

Varying factors, a mathematical relationship that relates optimization parameters and factors, the so-called response function, was found:

$$
\mathrm{Y}_{1}=\mathrm{f}_{1}\left(\mathrm{x}_{1}, \mathrm{x}_{2}, \mathrm{x}_{3} \ldots . . \mathrm{x}_{\mathrm{i}}\right)
$$

A statistical analysis was performed. The errors of the experiments' reproducibility were determined, and the significance of the obtained regression equations was established.

The regression equation in natural values:

$$
\mathrm{Y}_{\mathrm{r}(\text { nat. })}=20.6-6.3 \mathrm{~V}+0.52 \mathrm{~T}+0.84 \mathrm{C}
$$

A correlation analysis was carried out for each variant of the study of the dissolution dynamics of the mineral-containing load (marble, dolomite, gypsum, a mixture of dolomite with gypsum) with various optimization factors. 
The error of experimental data and calculated results was 5-7\%, therefore, the obtained regression equations adequately described the experimental data [5]. Also, experimental studies of deodorization and disinfection equipment were conducted. After the filter with activated carbon, water samples were taken for organoleptic analysis (Table 1).

Table 1. Analytical data of water samples.

\begin{tabular}{|l|c|c|c|}
\hline \multicolumn{1}{|c|}{ Indicator } & $\begin{array}{c}\text { Before } \\
\text { deodorizing filter }\end{array}$ & $\begin{array}{c}\text { After } \\
\text { deodorizing filter }\end{array}$ & $\begin{array}{c}\text { Sanitary Regulations and } \\
\text { Norms 2.1.4-1074-01 }\end{array}$ \\
\hline Smell at $20^{\circ} \mathrm{C}$ & 1 & 0 & 0 \\
Taste at $20^{\circ} \mathrm{C}$ & 3 & 0 & $\leq 2$ \\
Chromaticity, degrees & 30 & 10 & $\leq 20$ \\
Turbidity, mg / & 2.0 & 0.5 & $\leq 1.5$ \\
\hline
\end{tabular}

It should be noted that the water after the deodorizing filter has the necessary purity (transparency) to treat it by UV irradiation.

In order to ensure the compactness of the plant and the minimal free space for its maintenance, the use of a compact UV-lamp of the type DB18-MF is provided.

Thanks to a special pilot insert, the flow of water around the quartz cover moves along a spiral trajectory, which intensifies the disinfection process [6, 7]. Calculations of the disinfecting ability of the UV-lamp and the dose of UV irradiation were made, as well as laboratory tests of samples of DB-18-MF lamps. Guaranteed water disinfection was provided. In the process of creating commercial prototype of water treatment plants, a set of studies was carried out to confirm the correctness of the problem solution. The scope of the test included:

- experimental studies using the planning method;

- study of the quality of water obtained in the water treatment plant by physicochemical, organoleptic and microbiological indicators;

- toxicological animal studies.

In the course of the study, the total operating time of the plant was about 850 hours. During this period, more than 60 water samples were examined for 15 quality indicators [8, 9]. The dynamics of changes in the total salinity of drinking water from the consumption of demineralized water, temperature and time since the plant was turned on was determined (Fig. 2).

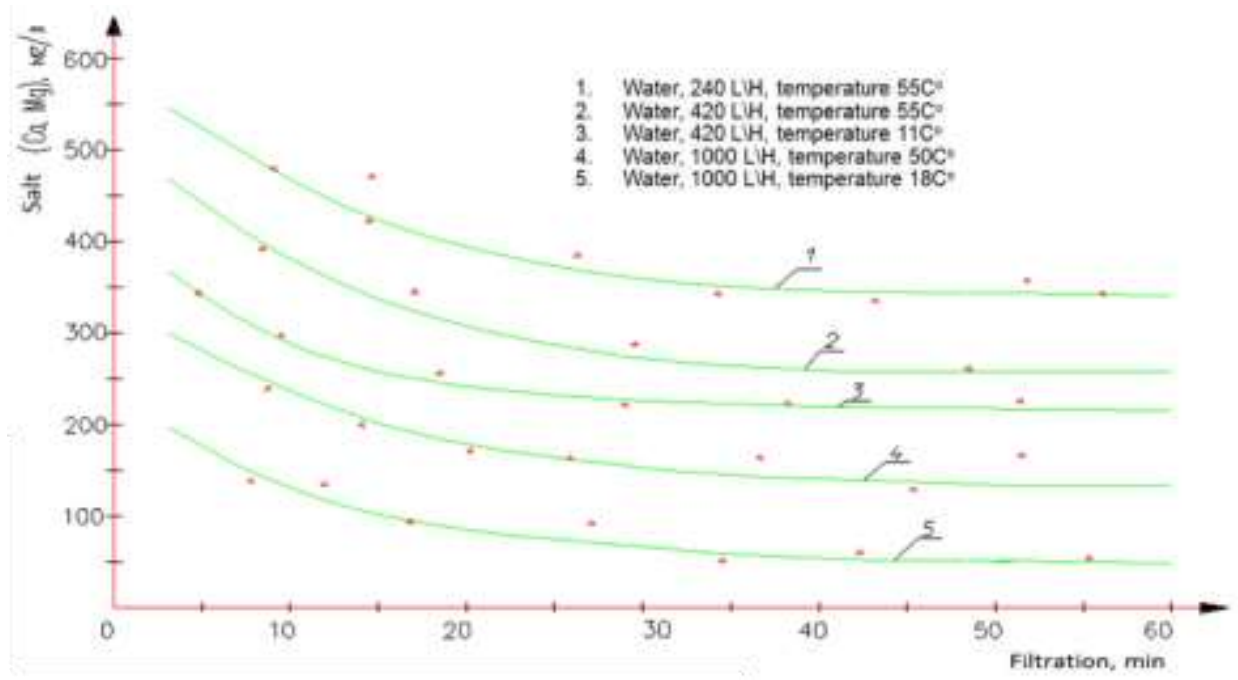

Fig. 2. Dynamics of changes in the total salinity of drinking water from water consumption, temperature and time since the plant was turned on. 


\section{Discussion}

Experimental and theoretical studies made it possible to determine the optimal operating conditions of the plant. Taking into account the results obtained in the course of the study, a hygienic conclusion about the possibility of practical application of a water treatment plant in submarines for the preparation of drinking water from demineralized water was obtained. It is shown that the control and measuring system implemented using logic elements can be designed using elements of a different basis for any autonomous objects [10].

The developed mathematical model of the automatic control system uses standard automation elements, and it is assumed that a specific analysis of the frequency and time characteristics can be performed using the well-known programs Mathcad, Matlab, Microcap-8, Mathematic-4, etc.

\section{Conclusion}

On the basis of the conducted analysis of modern methods and technical means for the implementation of water conditioning processes, the methods of mineralization, deodorization and disinfection were substantiated and selected, on the basis of which an improved technological scheme of water conditioning in an autonomous object was developed. A model sample of a water treatment plant with a detailed description of the methods and results of studies of filtering, deodorizing materials and disinfection equipment has been substantiated and developed. With the help of experimental and theoretical studies using the methods of multifactorial planning of the experiment and sanitary and hygienic studies, the optimal modes of water conditioning in the water treatment plant were determined.

\section{References}

1. R. Golov, I. Alkhimovich, V. Kazarnovskij, E. Ermolaeva, E3S Web Conf. 91 (2019) https://doi.org/10.1051/e3sconf/20199108052

2. I. Lukmanova, R. Golov, E3S Web of Conferences (2018) https://doi.org/10.1051/e3sconf/20183302047

3. L. Cabral, Research in Economics 70(4), 735-740 (2016)

4. A. Borboni, R. Faglia, Journal of Applied Mechanics, Transactions ASME 80(2), 021003 (2013) DOI: 10.1115/1.4007721 10.1115/1.4033831

5. H. Osman, Structure and Infrastructure Engineering 12(1), 108-121 (2016)

6. G. Seaden, M. Guolla, J. Doutriaux, J. Nash, Construction Management and Economics 21(6), 603-612 (2003)

7. H. Donner, H.-S. Song, M. Wilhelmsson, Journal of Housing Economics 34, 60-68 (2016)

8. R. Lee, A. Lukin, Russia's Far East: New Dynamics in Asia Pacific and Beyond (Boulder, Colorado, 2016)

9. L. Ustinovicius, R. Rasiulis, L. Nazarko, T. Vilutienè, M. Reizgevicius, Procedia Engineering 122,166-171 (2015)

10. V. Gasilov, N. Anisimova, I. Provotorov, MATEC Web of Conferences 106, 08035 (2017) DOI: $10.1051 /$ mateconf / 201710608035 